\title{
Prolonged Ventilation after CABG: an Important Issue
}

\author{
Leonardo Secchin Canale ${ }^{(1)}$ \\ Instituto Nacional de Cardiologia, Rio de Janeiro, RJ - Brazil \\ Editorial referring to the article: Risk Score for Prolonged Mechanical Ventilation in Coronary Artery Bypass Grafting
}

Coronary artery bypass surgery (CABG) is the most commonly performed heart operation in most countries, and its mortality and morbidity results are one of the most studied and scrutinized in the world. As a large operation involving long surgical times, sternotomy and cardiopulmonary bypass, long-term postoperative ventilation is a dreaded possible complication. Failure to wean from the ventilator can result both as a consequence of previous risk factors and as a cause of future morbidity and mortality. Not only it impacts patients' well-being and recovery times, but also can lead to further complications such as lung infections, sepsis, loss of general muscle function and need for tracheostomy. ${ }^{1}$

Therefore, the current study of Dallazen-Sartori et al. ${ }^{2}$ is a timely and useful attempt to better characterize the incidence and risk factors for the development of prolonged ventilation (PV) after CABG. As previous authors did before, the authors focus on preoperative and per-operative factors to try to expose, by multiple logistic regressions, which ones are causally associated to PV in order to construct a practical Risk Score. It is needless to stress the importance of such a study in our Brazilian population, which might behave differently from well-known previous reports ${ }^{3}$ from other countries. Unfortunately, we still face a paucity of local and regional studies that would better represent our own results, outcomes and challenges. The situation when we need to base our decisions in external sources of data instead of using the national one happens very often. The current study by Dallazen-Sartori et $\mathrm{al}{ }^{2}$ is an attempt to change that.

\section{Keywords}

Thoracic Surgery, Coronary Artery Bypass Surgery, Mechanical Ventilation, Grafting; Risk Factors.
The first aspect we should notice in the actual study is that PV is defined as longer than 12 hours of mechanical ventilation after arrival in the ICU. There is a divergence of definition in the current literature as to what constitutes "prolonged" need for ventilation. While the references provided by the authors indeed use 12 hours as the limit for PV definition, others ${ }^{1-3}$ and the STS database use the threshold of 24 hours. By "lowering the bar" for the outcome studied, it will most certainly increase its incidence (in this study 18.8\%) and we should keep that in mind when comparing results with previous studies. The advantage to utilize the 12-hour hallmark is that it may better represent the threshold where mortality and prolonged length of stay starts to climb. ${ }^{4}$ Therefore, it has a strong case to be viewed as a quality mark of our operations.

Possible risk factors elected by the authors to be investigated were adequately based in previous reports. The total number of patients included in this analysis (4,165 patients) is much larger than in many other studies conferring a great advantage on the power to draw sound conclusions. The time frame of observation used, over 20 years, was probably needed to achieve the present large cohort. It should be noted that such a wide period of observation might result in two different phenomena. On one hand, it avoids a time period bias (by precluding a too short period of observation when events could be mistakenly represented). On the other hand, by including the operation performed almost 24 years ago, it might have included scenarios and practices of extra-corporeal bypass circulation use and postoperative critical care that are no more in vogue today.

While many studies ${ }^{1,3-5}$ limit themselves to describe risk factors and their respective Odd Ratios to the PV outcome, Dallazen-Sartori et $\mathrm{al}^{2}{ }^{2}$ went a step further to empirically create a practical risk score and validated it with its own population. This was previously performed

Mailing Address: Leonardo Secchin Canale

Rua das Laranjeiras, 374. Postal Code: 22240-006, Rio de Janeiro, RJ - Brazil.

E-mail: leonardo.canale@gmail.com

DOI: https://doi.org/10.36660/ijcs.20210059 
by Legaré et al. ${ }^{6} 20$ years ago when a simple additive risk score could predict a patient being ventilated for more than $24 \mathrm{~h}$ with moderate precision. Differently from this Canadian previous risk score, Dallazen-cols. ${ }^{2}$ were able to instill different weights to different risk factors and also present us with a ROC curve.

The six risk factors that emerged as independent predictors of PV from the multiple logistic regression model are sound and in accordance with previous studies in this theme. The construction of an additive risk score could easily differentiate four different risk groups. The current risk score should be tested by other

\section{References}

1. Gumus F, Polat A, Yektas A, Totoz T, Bagci M, Erentug V, et al. Prolonged mechanical ventilation after CABG: risk factor analysis. J Cardiothorac Vasc Anesth. 2015 Feb;29(1):52-8. doi: 10.1053/j.jvca.2014.09.002.

2. Dallazen-Sartori F, Albuquerque LC, Guaragna JCVC, Magedanz EH, Petracco JB, Bodanese R, et al. Risk Score for Prolonged Mechanical Ventilation in Coronary Artery Bypass Grafting. Int J Cardiovasc Sci.2021;34(3):264-271.

3. Wise ES, Stonko DP, Glaser ZA, Garcia KL, Huang JJ, Kim JS, et al. Prediction of Prolonged Ventilation after Coronary Artery Bypass Grafting: Data from an Artificial Neural Network. Heart Surg Forum. 2017 Feb 24;20(1): E007-E014. doi: 10.1532/hsf.1566. institutions, which may behave slightly differently and start to become part of the preoperative evaluation of patients deemed candidates for CABG. One should notice that, when used in the preoperative setting, all but one variable (Bypass time) will be available for evaluation. The appropriate preop estimation on the risk of PV can affect our expectations and resource utilization of the postoperative period and even make us reconsider the decision to go on with the operation (in elective cases). It could be useful for clinicians and surgeons dealing with individual patients and possibly to ICU administrators in evaluating the quality of surgical and ventilation specific care.
4. Crawford TC, Magruder JT, Grimm JC, Sciortino C, Conte JV, Kim BS, et al. Early Extubation: A Proposed New Metric. Semin Thorac Cardiovasc Surg. 2016 Summer;28(2):290-299. doi: 10.1053/j.semtcvs.2016.04.009.

5. Branca P, McGaw P, Light R. Factors associated with prolonged mechanical ventilation following coronary artery bypass surgery. Chest. 2001 Feb;119(2):537-46. doi: 10.1378/chest.119.2.537.

6. Légaré JF, Hirsch GM, Buth KJ, MacDougall C, Sullivan JA. Preoperative prediction of prolonged mechanical ventilation following coronary artery bypass grafting. Eur J Cardiothorac Surg. 2001 Nov;20(5):930-6. doi: 10.1016/s1010-7940(01)00940-x. 